\title{
EN TORNO AL BARROCO RURAL EN LA TIERRA DE SANTIAGO: EL SANTUARIO DE A ESCRAVITUDE Y LA PROBLEMÁTICA DE LOS CENTROS ARTÍSTICOS
}

Data recepción: 2013/06/24

Data aceptación: 2013/10/28

Contacto autor: ivan.rega@hahs.udl.cat
Iván Rega Castro

Universitat de Lleida

\section{RESUMEN}

Este estudio se ocupa del retablo mayor de Nuestra Señora de la Esclavitud, vulgo A Escravitude, y trata de completar la historia de este santuario situado cerca de Padrón (Padrón, A Coruña). Merced a una cuidada y exhaustiva investigación en los archivos parroquiales del Archivo Histórico Diocesano de Santiago (AHDS), se pudo determinar qué artistas trabajaban allí a mediados del siglo XVIII; tal es el caso de José de Malbares († h. 1767). Así pues, éste texto quiere reunir las numerosas informaciones dispersas existentes sobre este escultor y entallador, junto con otros datos desconocidos hasta la fecha.

Palabras clave: Arquitectura barroca, retablística, centros artísticos del siglo XVIII, Santuario de A Escravitude, Ángel Antonio Mouriño, José de Malbares.

\section{ABSTRACT}

This study deals with the altarpiece of Nuestra Señora de la Esclavitud -or A Escravitude-; and it intends to complete the history of this santuary near Padrón (Padrón, A Coruña). Thanks to the exhaustive analysis of the parish archives at the Archivo Histórico Diocesano de Santiago (AHDS), it can be determined which artists worked there in the middle of the eighteenth century; this is the case of José de Malbares († h. 1767). Thus, this study unites numerous dispersed materials, with the addition of heretofore-unknown documents concerning the wood-carver.

Keywords: Barroque architecture, altarpieces, artistic centres of the eighteenth century, the Sanctuary of A Escravitude, Ángel Antonio Mouriño, José de Malbares.

En 1734, un cura de Arousa dio cuenta de una visita «[...] a la feligresía de Balga [sic] buscando al Maestro de obras en la [freguesía de Cruces, Padrón] de Nuestra Señora de la Esclavitud [...]»; así mismo apuntó que «[...] vino buscándole a su casa, feligresía de Valga»². Desgraciadamente calla el nombre de este maestro de obras que -claro está- era vecino de Valga (Pontevedra) y, a tenor de lo referido, responsable de las obras del santuario de Nuestra Señora de la Esclavitud, vulgo A Escravitude (Padrón, A Coruña). Según todas las noticas, estas echaron a andar después de 1732; si bien, en verdad, poco se sabe con certeza -su cronología está en relación con unos hechos tenidos por milagrosos, acaecidos en $1732^{3}$. Se trata, en todo caso, de una de las fábricas más importantes del Barroco rural en la Tierra de Santiago, casi siempre puesta en manos de discípulos de Fernando de Casas -desde Otero Túñez- o Simón Rodríguez, como por ejemplo, fray Manuel de los Mártires $(+1775)^{4}$. (Fig. 1)

Era vecino de Valga, por entonces, un tal Ángel Antonio Mouriño; el cual en noviembre de 1739 se declara «[...] Maestro de canteria vezino del Lugar de Rajoy y de esta mesma feligresía» al suscribir contrato para hacer el cuerpo de la iglesia de San Miguel de Valga (Valga, 


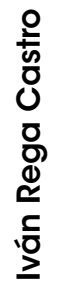

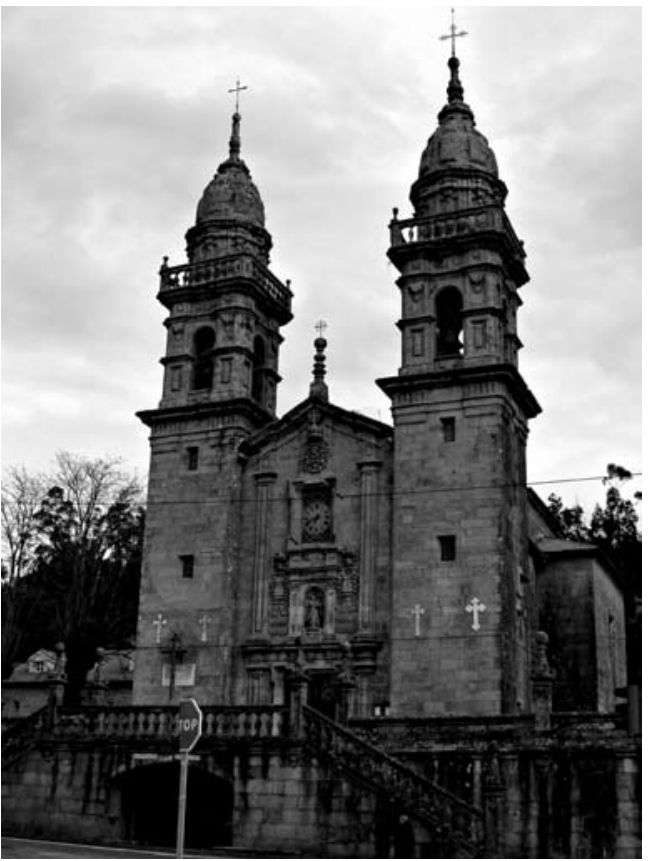

Fig. 1. Santuario de Nuestra Señora de la Esclavitud, esto es, A Escravitude (Padrón, A Coruña), entre 1732-1750 (?). Foto: I. Rega Castro

Pontevedra), con su fachada y torre, a imagen y semejanza de la de San Xulián de Requeixo (Pontecesures, Pontevedra) -sin lugar a dudas, también levantada por este Ángel Mouriño ${ }^{5}$. Uno de los más productivos maestros de mediados del siglo XVIII en el valle del Sar y en el país Ullán, quien ocupó un lugar más o menos destacado del campo de producción, en posiciones medias o "medio-bajas", sobre el área que delimitan «la villa del Padrón, villa de Caldas y otras partes [...]»-sobre la depresión meridiana-y hacia el interior de la jurisdicción de Baños de Cuntis (Cuntis, Pontevedra) ${ }^{6}$.

Es así que su nombre está relacionado, a mi juicio, con lo trazado u obrado en el Santuario de A Escravitude -¿de qué manera?-; habida cuenta que pocos son los maestros de obras con casa en la feligresía de Valga, en el tercio central del siglo XVIII, y con tal competencia en el oficio. En efecto, en los Libros de las Respuestas Generales del Catastro de Ensenada, debajo del rótulo «Canteros» se cuentan tres oficiales y un

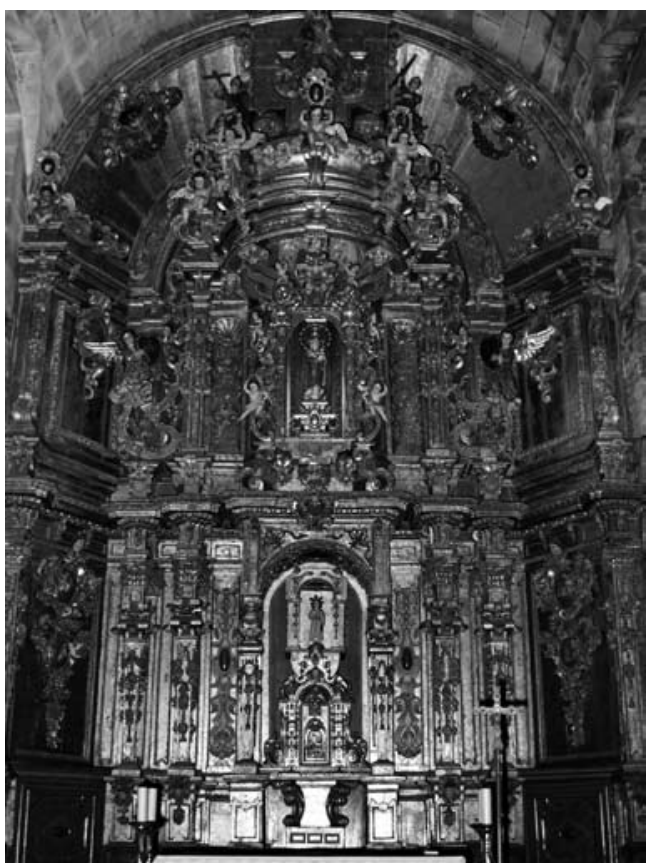

Fig. 2. Retablo mayor del Santuario de A Escravitude, entre 1739-1742. Foto: I. Rega Castro

maestro de obras: Ángel Mouriño, a quien «[...] sele regularon de utilidad cinco reales de vellón secos [cantidad nada desdeñable] el dia que trabaxa» ${ }^{7}$; por tanto, sólo él aparece censado en agosto de 1752, en la jurisdicción de Cordeiro, en la feligresía de Valga.

Así mismo, encaja en el molde que perfilan las noticias de Santiago de Carril (Vilagarcia de Arousa, Pontevedra), y, como se dijo, en relación con un

[...] viaje que a echo a Santiago [el escribano] al ganar el Despacho, venido a esta villa [Carril] y de ella partido a la feligresía de Balga buscando al Maestro de obras en la de Nuestra Señora de la Esclavitud, nombrado por el señor Provisor para el renocimiento del estado de la yglesia [las cursivas son mías] (* Véase nota 2)

\section{Obras sin nombres}

Pero más que la arquitectura en piedra, interesa poner el foco de atención sobre la hechura y composición del retablo mayor de Nuestra 
Señora de la Esclavitud, llevado a cabo entre 1739-1743 (aprox.). Ahora bien, el principal problema para su estudio sigue siendo, a día de hoy, justamente esa escasez de noticias y falta de documentación; ya de las obras de cantería, ya de la arquitectura en madera. (Fig. 2)

En todo caso, se sabe -ya desde Couselo Bouzas- de la escritura pública del ajuste entre «[...] D. Fernando Gill de Riuera y Araujo Canonigo Magistral prevendado en la santa ynsigne y mas antigua Yglesia de ssta. Maria de Iria Flavia de esta dicha villa, juez veedor zelador y conservador de el santuario de nra. ssra. de la esclavitud exsistente en la feligresia de ssta. Maria de Cruces», y, de la otra parte, «[...] Alejandro Dominguez maestro de el arte pincelista y dorador vezino de la ciudad de Tuy» para la pintura y dorado de su altar mayor ${ }^{8}$.

Como es bien sabido, esta fue dada en Padrón, el 23 de agosto de 1743.

Es justo decir, por otra parte, que la obra urgía; ya que precisamente desde 1732 -según González Lopo- el número de limosnas y misas que se disponían en los testamentos de vecinos de Santiago de Compostela con destino al Santuario de A Escravitude aumentó considerablemente -representando nada menos que el 10 por ciento del total, entre 1731-17609. Aunque nada más se sepa de las obras del Santuario, las limosnas y donaciones, sin lugar a dudas, aseguraron el trabajo continuado y favorecieron la contratación de maestros de arquitectura y cantería, si no de prestigio, de reconocida valía. Con certeza los trabajos dieron inicio entre 1732-1734, a tenor de la presencia del «Maestro de obras en la [feligresía] de Nuestra Señora de la Esclavitud»; tal vez Ángel Mouriño, el cual ya está ocupado en otros quehaceres a finales de 1739. Siendo así, por entonces debería estar la cabecera cerrada y la iglesia muy avanzada, a fin de poder llevarse a cabo, a continuación, el ajuste y hechura de su retablo mayor.

De lo que no cabe duda es que la jerarquía avivó esta empresa -siempre bajo tutela del cabildo de Santa María de Iria y la vigilancia de las autoridades eclesiásticas del Arzobispado-; poniendo todo el empeño «[...] a fin de que [...] el santuario estubiese con mas decencia, y se le diese mayor culto y veneración».
Así que no hay que extrañarse porque los de Santiago de Carril fueran «[...] buscando al Maestro de obras en la [feligresía] de Nuestra Señora de la Esclavitud, nombrado por el señor Provisor para el renocimiento del estado de la yglesia [las cursivas son mías]»; habida cuenta que los maestros de arquitectura y escultura enrolados en la fábrica de A Escravitude contaron, al parecer, con el beneplácito y confianza de las autoridades eclesiásticas.

En cualquier caso, años más tarde, ya se pensaba en hacer los retablos colaterales, a tenor del «Contrato obligación y fuerza [...]» que se suscribió el 3 de agosto de 1749 para «[...] dorar los dos retablos colaterales [de la Visitación de la Virgen a Santa Isabel, en el lado del evangelio, y de Santa Salomé, en la epístola] que se hallan en la capilla y santtuario de nuesttra señora de la Esclavittud» ${ }^{10}$. Este trabajo se le entregó a «[...] Juan Manuel de Leis y Thomas de Arosa su oficio de pintores vezinos desta ciudad [Santiago de Compostela]»; los cuales, por su parte, se comprometieron a darlo hecho para «[...] denttro de tres meses y medio» (Fig. 3).

Una vez más el Arzobispado hizo de acicate, dado que allí

[...] dijeron haver llegado a su [conocimiento] que por el Sr. D. Juan Policarpo de Mendoza canonigo cardenal dignidad en la santa Apostolica Iglesia de señor Santiago gobernador provincial y vicario General en estta Ciudad y su Arzobispado, se ynttentava mandar dorar los dos retablos colaterales que se hallan en la capilla y santtuario de nuesttra señora de la Esclavittud [...]

y así, sabedores de esto, «[...] pasaron a berlos y reconocerlos a ttoda su sattisfacción» ${ }^{11}$.

Por consiguiente, es un hecho que la participación de las jerarquías eclesiásticas en la construcción y su administración fue en aumento, a medida que crecía la fama del Santuario - a decir de Otero Túñez-; hasta el punto que la Mitra autorizó por 1769 la fundación de tres capellanías para atender el culto ${ }^{12}$. Poco después, en 1771, se estableció canónicamente la Cofradía de María Santísima de la Esclavitud, encabezándola el Papa Clemente XVI, seguido por el Rey -Carlos III- y el arzobispo D. Bartolomé de Rajoy y Losada $^{13}$. 


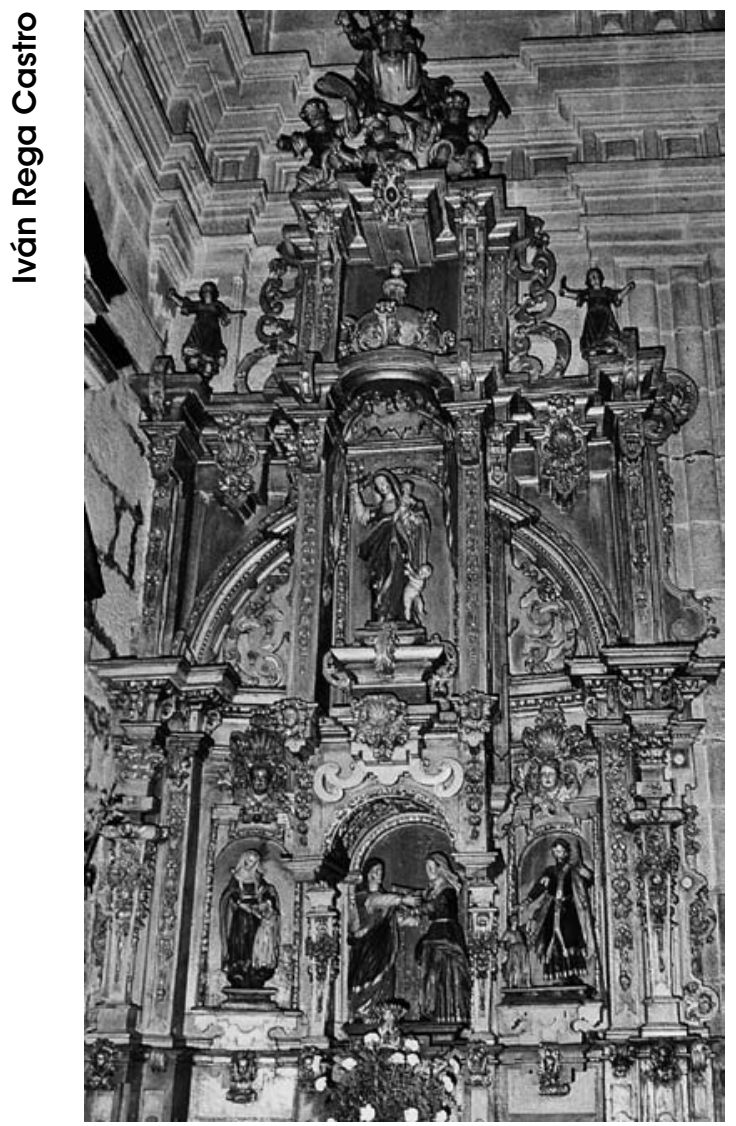

Fig. 3. Retablo colateral de la Visitación de la Virgen a Santa Isabel, en el lado del evangelio, del Santuario de A Escravitude, ant. 1749. Foto: I. Rega Castro

\section{Un ensayo de atribución}

Pues bien, desde Otero Túñez, el altar mayor de la Virgen de A Escravitude ocupa un puesto muy destacado entre los retablos con estípites de la Tierra de Santiago. Siendo así, López Vázquez lo consideró «el gran conjunto retablístico del momento» -esto es, de los años 17401749-14; su «gran riqueza y fastuosidad» -en palabras de Otero Túñez-, su movilidad, juegos de volúmenes, la multiplicación de soportes y de placas, hablaría de un lenguaje a derivar de Simón Rodríguez, según García Iglesias. En cualquier caso, su autor, a juicio de Folgar de Calle, no hay duda, conoció las "grandes máquinas compostelanas» ${ }^{15}$. Por tanto, la incógnita pasa, no sólo, por saber cuándo se talló, ensambló y asentó, y quien lo hizo; si no también cómo negarle su centralidad a Santiago de Compostela, frente a otros centros productores de la Galicia atlántica, como Noia, Pontevedra o - ¿por qué no?- Padrón - Iria Flavia.

Pero, entrando a estudiarlo, lo mejor es empezar por el principio; y tratar de "descomponer" fondo y estructura. Habida cuenta que el altar mayor de Nuestra Señora de la Esclavitud se articuló en base a una estructura "doble", que sumó un gran arco de triunfo y un armazón compuesto de predela, dos cuerpos y ático. Se construyó conforme a una planta ochavada, subyugada al protagonismo de la calle principal, muy desarrollada y de grandes dimensiones; así mismo esta se abre hasta su base para alojar, de esta forma, el tabernáculo. Sobre la predela -compuesta por banco y sotabanco-, se levantó una estructura lineal y sometida al plano de fondo -al menos en el cuerpo bajo-, articulado con dos pares de estípites, con sus retropilastras. (Fig. 4)

Hay que poner de relieve, además, que el tipo de soporte coincide, en líneas generales, con lo ejecutado por Miguel de Romay y Manuel de Leys con destino al tabernáculo de los benedictinos de Santiago de Compostela (1730-1733) ${ }^{16}$. Nótese que su cuerpo, cajeado, se engalanó con guirnaldas que desbordan hacia los ángulos; sobre este se asienta un abultado bocel, luego el cuello del estípite y un filete que recoge el peso del dado, haciendo las veces del capitel: con un festón de flores, que pende de las volutas de sus ángulos, y coronado por un ábaco de paredes cóncavas, tal y como se talló para el edículo el altar mayor de A Escravitude.

Pues bien, el hecho que ni Fernando de Casas, ni Simón Rodríguez, hayan recurrido en sus retablos a los estípites como soportes principales de la estructura, empujó a Otero Túñez a decir que «[...] sólo sus discípulos, como Fr. Manuel de los Mártires, se atrevieron a utilizarlo como soporte fundamental [...]», al menos dentro de las murallas de Santiago de Compostela. Como se sabe, el uno y el otro, se decantaron, durante el segundo cuarto del siglo XVIII, por el uso de la columna panzuda; sólo sus epígonos le otorgaron al estípite su merecido protagonismo ${ }^{17}$, ya que será especialmente por los años 1730-1739 


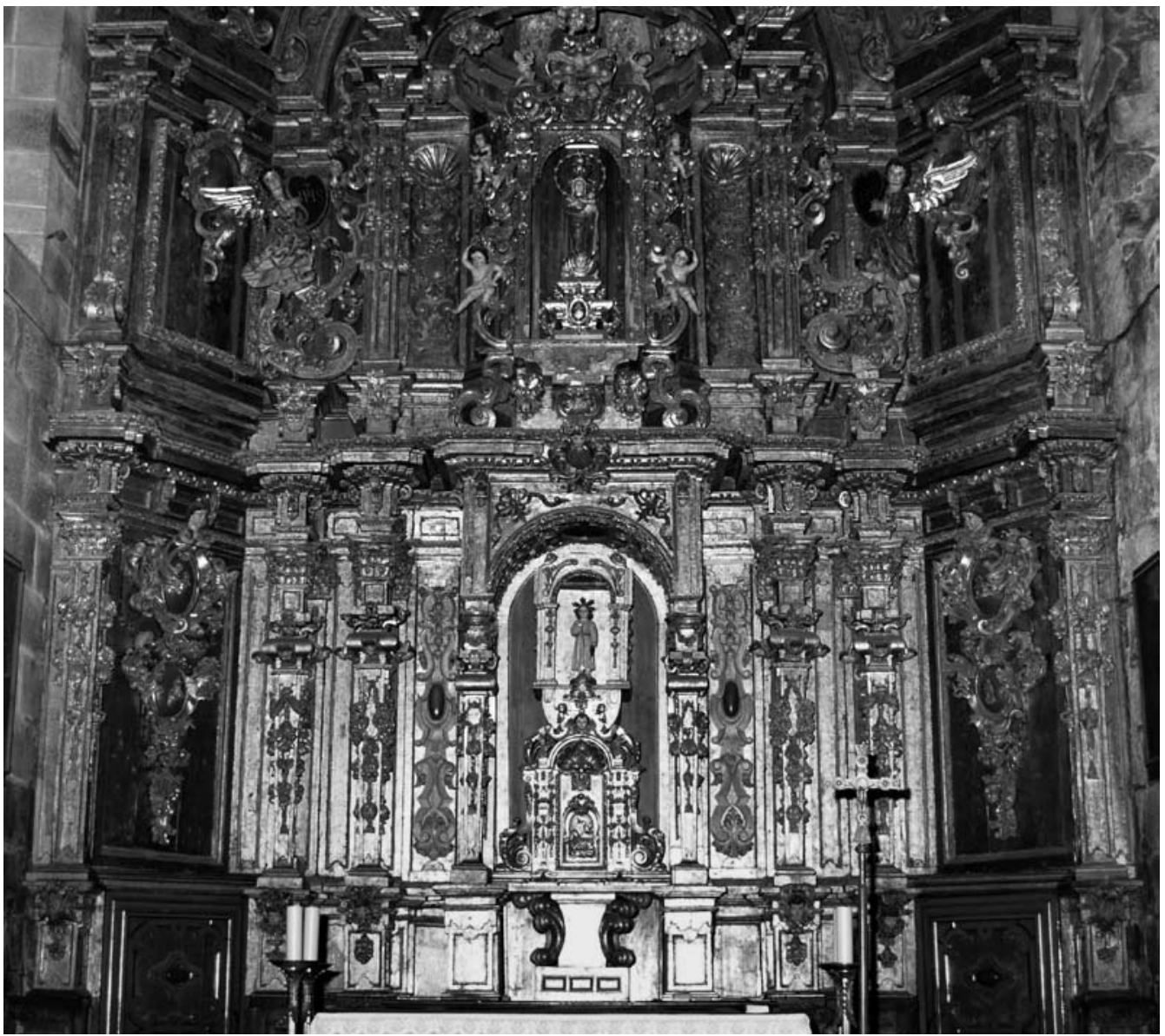

Fig. 4. Cuerpo central del retablo mayor del Santuario de A Escravitude. Foto: I. Rega Castro

(aprox.), cuando su uso se generalice en el Occidente gallego ${ }^{18}$.

A este respecto, se debe poner de relieve que fue el aparto de producción de la villa de Noia el que desempeñó una función, sin lugar a dudas, determinante en la difusión y "canonización" de los retablos de estípites a partir de 1733 (aprox.); de un modo particular, en su incorporación a los repertorios y usos artísticos del siglo XVIII ${ }^{19}$. Pues bien, precisamente en aquellos años, un noiés se asentó en la feligresía de Santa María de Cruces: José de Malbares († h. 1767).

Dijo Couselo Bouzas que la villa de Noia era

[...] el lugar de su naturaleza, en donde debió nacer a últimos del siglo XVII. Ha recorrido en el ejercicio de su profesión muchas parroquias de la Diócesis, pues parece que trabajaba las obras en los sitios que se las encargaban²0.

Si bien, tal movilidad de talleres y maestros ha de verse en un contexto en que usualmente la oferta de mano de obra era no sólo suficiente, sino abundante.

Por lo demás, se sabe que en julio de 1744, él ajustó con D. Juan Antonio de España y Luna, señor de la Casa de Parada y alcalde más antiguo de la ciudad de Santiago de Compostela, el retablo de la capilla de Nuestra Señora de la Blanca, en la Catedral -sita en la girola, entre las románicas de San Juan Evangelista y del Rey de Francia, o del Salvador-, por unos 2.000 reales. 
Por desgracia este no se conserva actualmente, ya que se desmontó en 1906; sí, en cambio, la imagen de la titular, que talló, por 1744, Gregorio Fernández Prieto ${ }^{21}$. Ahora bien, ante la Casa de España y Luna, José de Malbares firmó como vecino de Santa María de Cruces (Padrón, A Coruña), habida cuenta que, seguramente antes del verano de 1743, trabajó en el santuario de Nuestra Señora de la Esclavitud. Por tanto, apenas un año después del asiento de su retablo mayor; tan sólo unos meses después del final de los trabajos de pintura y dorado, que tenían que ultimarse para febrero de 1744. En todo caso, hay que subrayar que en la Galicia rural -igual que en el resto del reino- no se acostumbró a obligar al maestro a trasladar su taller a la localidad en que iban a trabajar22.

Pero poco después de emplearse en la Catedral, volvió a Iria Flavia; así, Pérez Piñeiro lo localizó trabajando en la iglesia de Santa María de Leiro (Rianxo, A Coruña), entre 1746 y $1747^{23}$.

Siendo así, es posible que José de Malbares fijara su taller en el valle del Sar y, más concretamente, en la feligresía de Santa María de Cruces - ¿entre 1740-1744?-, a fin de trabajar en sus iglesias. Son pocos los casos en que se le solicite a un artífice el establecimiento de su taller y residencia donde iba a trabajar, como subrayé; con esto, lo que se quería, con toda seguridad, era asegurarse la dedicación y seguimiento de los trabajos y, de esta manera, prevenir los riesgos del transporte. Lo que, en última instancia, nos da idea de la envergadura de la obra que le ocupó en la feligresía de Cruces. Pero ¿cuál?

En honor a la verdad, no queda otra que admitir que ya M. Murguía barajó la hipótesis de que un desconocido "José Malvares», quien «para el caso puede considerárselo compostelano», trabajara en los retablos del Santuario de A Escravitude ${ }^{24}$. Si bien fue Tilve Jar quien hizo el mayor esfuerzo de estudio y catalogación, encaminado a poner a José de Malbares en el lugar que le correspondía en la retablística de la Galicia atlántica, en especial en Arousa e Iria Flavia. Un artista longevo, con una actividad que se prolongó entre 1725-176725, al que se le llamó "Maestro de entallador», "escultor», «maestro del arte de escultor» O "maestro de esculptura y pintura».
Por otra parte, en relación con su nombre, es importante señalar que el nombre/apellido que la historiografía aceptó -o por mejor decir, su ortografía-, a propuesta de Couselo Bouzas, esto es: "José Benito Malvárez», no se correspondió casi nunca con el que registró la documentación - cuentas de Fábricas, órdenes de pago, contratos, La Única, etc.-, ni con el que usó como firma: «José de Malbares».

\section{Acerca de José de Malbares}

Pues bien, en el sur de la vieja provincia de Santiago -hoy de Pontevedra-, para la iglesia de San Miguel de Valga (Valga, Pontevedra), José de Malbares hizo el retablo mayor y su custodia en 1725, y, más tarde, en 1727 trabajó en Santo Tomé de Caldas (Caldas de Reis, Pontevedra) ${ }^{26}$. En la ría de Arousa, según Tilve Jar, lo hizo en los colaterales de San Pedro de Dimo (Catoira, Pontevedra) por 1734; entre 1734-1736, en la feligresía de San Xoán de Baión (Vilanova de Arousa, Pontevedra) se encargó del altar mayor y su imaginería, «[...] en conformidad de la planta que para el abia echo» ${ }^{27}$. Si bien, infelizmente, muy poco resta de su producción anterior a 1739, puesto que no quedó en pié ninguno de sus retablos.

En julio de 1739, Rodríguez Fraiz le encontró en San Pedro de Campañó (Pontevedra, Pontevedra), ajustando, junto a Benito Rey Somoza, la hechura del retablo mayor; donde afirmó ser «[...] vecino de la feligresía de San Pedro de Dimo [arciprestazgo de Arousa] deste Arzobispado y estante en esta feligresía $[\ldots]{ }^{28}$. Ahora bien, estos obradores rurales las más de las veces tenían una vida corta, determinada por la carga de trabajo -tal vez allí vivió José de Malbares por los años 1730-1739-; eran, pues, talleres "de paso", en palabras de Goy Diz, los que una vez cumplido el encargo, se desmontaban y se trasladaban al lugar de residencia del maestro ${ }^{29}$. Por tanto, no hay que extrañarse porque en julio de 1745 declarase ser, otra vez, «[...] Maestro de escultura, arquitectura y pintura vezino de la villa de Noya [las cursivas también son mías]», ante los vecinos y mayordomos de Santa Columba de Louro (Valga, Pontevedra), en la jurisdicción de Cordeiro, donde se encargó de «[...] la echura de una ymagen de un crusifigo [sic] de cuerpo 
entero para desendimiento con su sepulcoro $[\mathrm{sic}] »^{30}$. Poco después se trasladó, una vez más, al sur del río Umia, dado que lo encontramos, entre 1747-1748, en San Pedro de Lantaño (Portas, Pontevedra), ocupado en «[...] diferentes obras que hizo para la yglesia de esta freguesia $[\ldots])^{31}$.

Por consiguiente, el suyo fue uno de los talleres más activos de la ría de Noia, y, su gubia, una de las más prolíficas del sur de la Diócesis; un hecho puesto ya de relieve por Rodríguez Fraiz y Tilve Jar. Pero no sólo ensambló retablos, y talló adornos, junto a la turma de ayudantes y oficiales con que le imaginó Rodríguez Fraiz ${ }^{32}$; no sólo se encargó de la imaginería, y de su pintura, dorado y estofado, sino que también dio trazas, a veces para otros artistas. De hecho, hay que pensar que el noiés ocupó una posición destacada en el campo de producción, al menos en Padrón y su tierra, ya por los años medios del siglo XVIII, cuando proyectó el retablo mayor de la feligresía de Louro, entre 1763-1765; entonces cobró seiscientos reales, cantidad más que generosa, sólo «[...] por la planta de dicho retablo $[\ldots])^{33}$.

En resumidas cuentas, nos las habemos con un maestro que montó y desmontó su obrador a lo largo del segundo cuarto del XVIII, trabajando de comarca en comarca: primero en Arousa, luego en O Salnés, y, finalmente, en Iria Flavia y la vega de Padrón. Últimamente, Fraguas y Fraguas lo censó, en 1752, ya como vecino de la villa de Padrón ${ }^{34}$, y, es de suponer, que terminó sus días trabajando para las feligresías de Iria Flavia y el valle del Sar. En efecto, en agosto de 1752, en los "Libros de las Respuestas Generales», bajo el rótulo de Escultor, aparece "Jose Malbares», afirmándose que a «este le regulan quatro reales el dia que trabaxa [...]» ${ }^{35}$.

En todo caso, a favor de la atribución y/o presencia de José de Malbares en la obra del retablo mayor del Santuario de A Escravitude hay que tener en cuenta, junto a su periplo vital, su trayectoria profesional y su conocimiento de los estilos de Simón Rodríguez y Manuel de Leys; tal y como se plasmó en el altar mayor de San Pedro de Campañó -entre 1739-1740-, al hacer uso de "espejos" y óvalos con sus cuatro cabezas de clavo dispuestas en cruz, placas, recortes, asas y cartones. Además, sorprenden poderosamente las semejanzas no tanto a nivel de macroestructura, sino antes bien de micro-estructura. Así pues, al descomponer la estructura en unidades más pequeñas, pero dotadas de autonomía, se descubren continuamente patrones derivados de los esquemas y fórmulas codificados a lo largo de la primera mitad del siglo XVIII; como por ejemplo, el cuerpo bajo: con una micro-arquitectura pensada para la "exposición" y proyectada alrededor del tabernáculo.

En principio, no debería prestar atención al edículo-expositor, ya que Otero Túñez afirmó que había sido «[...] restaurado recientemente [antes de 1951], según trazas del gran escultor Asorey [†1961]» ${ }^{36}$. (Fig. 5) No obstante, entre las fotografías que formaban parte de la exposición Una mirada de antaño: fotografías de Ruth Matilda Anderson en Galicia, organizada por la Fundación Caixa Galicia (2009-2010), se encuentra una catalogada como «Santuario, altar mayor, A Escravitude (A Coruña), 5 de octubre de 1924» -desconocida por la historiografía gallega-, que

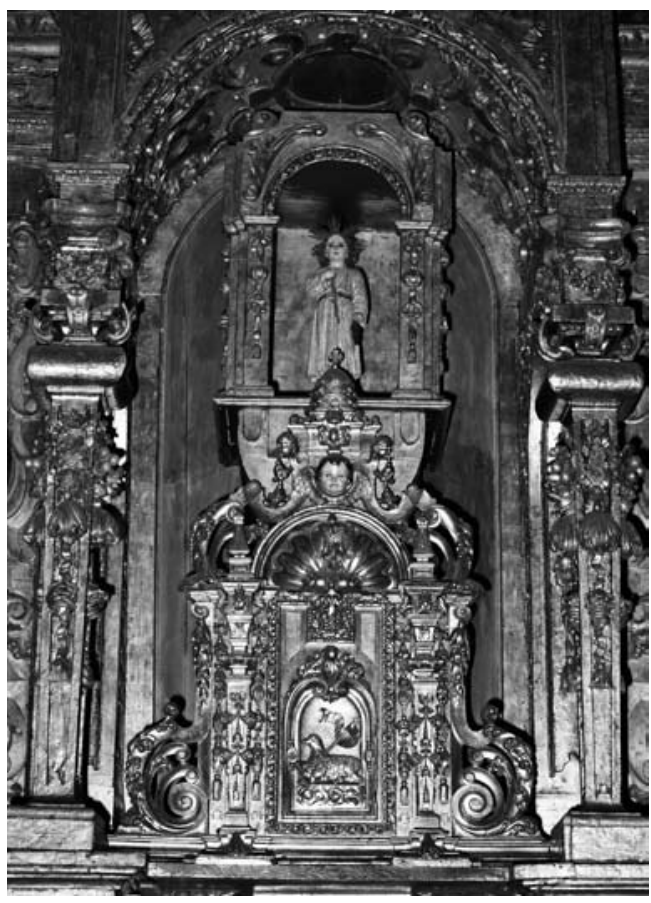

Fig. 5. Detalle del edículo-expositor del altar mayor del Santuario de A Escravitude, entre 1739-1742. Foto: I. Rega Castro 
muestra una vista general de la capilla mayor, donde -a pesar de la lejanía- no se aprecian importantes transformaciones o cambios en la imagen de conjunto ${ }^{37}$ (Fig. 6). Es decir, aparentemente se mantuvo intacta la unidad de estilo del tabernáculo y el edículo-expositor; hayan sido restaurados o no. Siendo así, hay que buscar su antecedente en el quehacer de Simón Rodríguez, en relación con una gramática de composición basada en placas y recortes; en sus microarquitecturas para edículos eucarísticos, cuyo modelo último se materializa, como se sabe, en el retablo mayor de la iglesia de la Compañía de Jesús ${ }^{38}$.

Por otra parte, en el segundo cuerpo, el soporte se simplificó, cambiando los estípites por pilastrones; con su fuste recorrido por sartas de frutas, encajándose en el entablamento, sin elementos de mediación. Además, en los flancos,

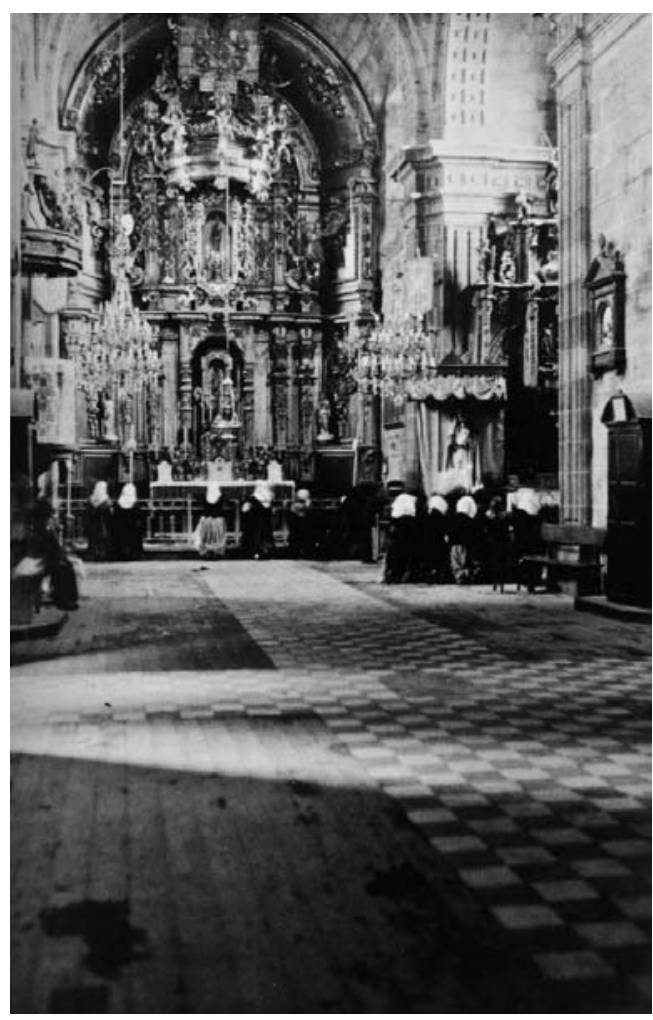

Fig. 6. Ruth Matilda Anderson, «Santuario, altar mayor, A Escravitude (A Coruña), 5 de octubre de 1924», the collections of Prints and Photographs, The Hispanic Society of America, Cat. Anderson 1808 se sustituyen los soportes por tornapuntas recortadas y de apariencia metálica, sobre las que cabalgan ángeles, multiplicándose las curvas y contra-curvas. Con razón García Iglesias subrayó que era «[...] brillante el modo de concebir el rico encuadre que enmarca la figura de la titular [...], lleno de dinamismo y de variedad de formas» ${ }^{39}$; y donde se concentra, sobre manera, el adorno. (Fig. 7) Por lo demás, en el plano estructural, su composición responde a soluciones más o menos frecuentes en la retablística de la primera mitad del XVIII; ya que el uso de una hornacina enmarcada y flanqueada por cartones, representó una fórmula ordinaria en el círculo de Simón Rodríguez y/o Fernando de Casas. Así, por ejemplo, años más tarde, Francisco de Lens en el altar mayor del Colegio de las Huérfanas (1756-1758) echó mano, en el ático, de dos ángeles portadores de escudos de formas asimétricas y acorazonadas, sentados sobre volutas, flanqueando la caja principal, y descansando, estas, sobre pilastrones cajeados ${ }^{40}$. (Fig. 8)

En último lugar, pero no por ellos menos importante, imposible no caer en la cuenta -en el análisis compositivo del ático- de las semejanzas con otra "máquina" de la primera mitad del XVIII, ya que la solución de una gran cúpula destinada a proteger a la Virgen María está relacionada con el retablo mayor de San Martiño Pinario. Hay que tener presente que Fernando de Casas trazó un intradós gallonado, desbordante de decoración, para su cupulín, sin duda, una fórmula que se repitió en este altar mayor del Santuario de A Escravitude, al igual que los pinjantes de su borde.

Por todo ello, se puede concluir, a ciencia cierta, que el autor de la planta del altar mayor de la Virgen de A Escravitude poseía un estrecho conocimiento de la obra de aquellos arquitectos del siglo XVIII, por lo que no parece descabellado suponerle trabajando a las órdenes de Simón Rodríguez y Fernando de Casas. Con certeza, las grandes proporciones del retablo exigieron la participación de un maestro de valía, con suficiente pericia para plantear coherentemente las trazas de una obra de cierta envergadura. Puesto que gran parte del obrador de San Martiño Pinario -Francisco de Casas, Domingo de Romay, Andrés Ignacio Mariño, Bernardo García, 


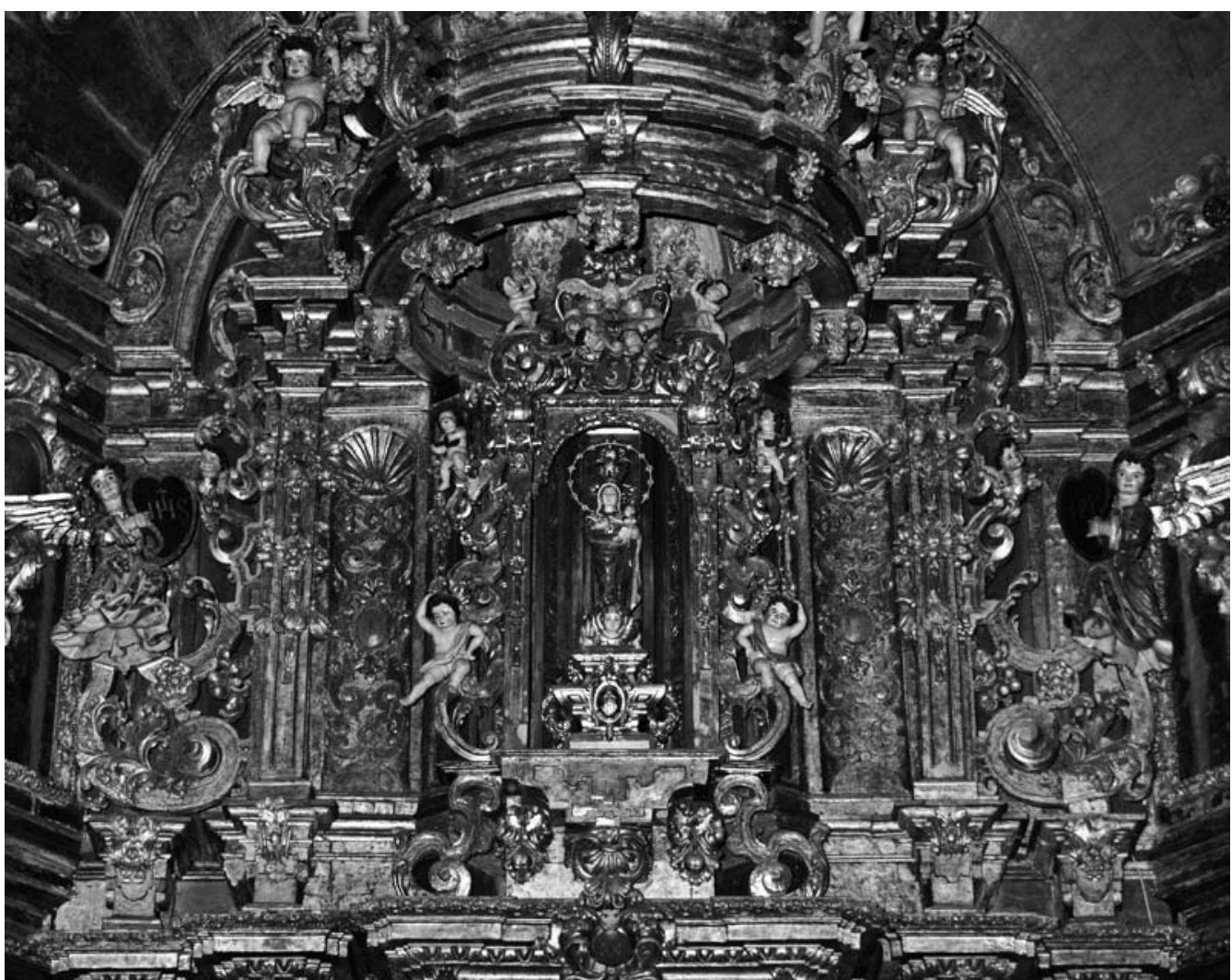

Fig. 7. Detalle del encuadre de Nuestra Señora de la Esclavitud, del retablo mayor. Foto: I. Rega Castro

Manuel de la Iglesia...-, trabajaba ya entre 1742 y 1745 en los retablos colaterales del crucero, y entre marzo de 1742 y abril de 1747 en el retablo mayor de la capilla del Hospital de San Roque, pocos son candidatos de cierto relieve que podrían apuntarse como "autores". Si bien, en este juego de hipótesis, el entorno de Miguel de Romay -quien seguía vivo por marzo de 1742-41 sigue siendo, sin lugar a dudas, la apuesta más segura: sólo Manuel de Leys († h. 1766) -u otro muy cercano a él, como Francisco das Moas ( $+h$. 1769) - podría estar a la altura; pero sin contar con él exclusivamente, dado que se sabe más inclinado a hacer uso de pilastras y columnas panzudas, antes que de estípites. En primer lugar, conviene recordar que Leys fue su aparejador, cuando Miguel de Romay se puso al frente de la obra del altar mayor de los benedictinos de San Martiño Pinario, y, por otra parte, se puso tanto a las órdenes de Fernando de Casas, como de
Simón Rodríguez. Al tiempo que su trabajo junto a los benedictinos, desde el verano de 1730 , significa un contacto temprano con el uso del estípite barroco.

\section{(Re)pensar los centros artísticos}

Es un hecho que cada uno de estos artífices/ artistas desarrolla su actividad en un territorio o marco geográfico, con un radio de acción más o menos amplio; y es en relación con este eje arte-lugar donde conviene hacer hincapié en la noción de "centros artísticos", a fin de hacer posible el correcto uso de la metodología y, en definitiva, una exacta atribución de sentido ${ }^{42}$.

En las circunstancias de la Galicia barroca, la libertad de movimientos de estos "productores" era, prácticamente, completa -es lógico que así fuera-, en relación únicamente con la demanda y con el aparato de producción que conformaron 


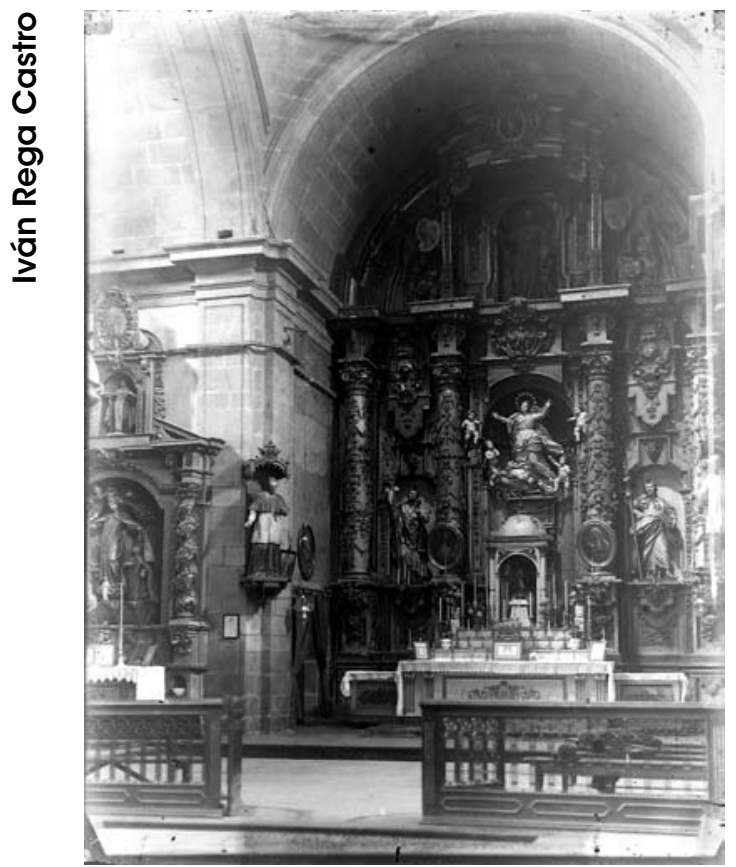

Fig. 8. Manuel Chicharro, altar mayor del Colegio de las Huérfanas, colección fotográfica del Instituto de Estudios Gallegos Padre Sarmiento (IEGPS), ref. 48(155-H)

los centros artísticos o focos. Si bien, de esto ya dan buena cuenta los ajustes de obra y cartas de pago de los archivos parroquiales (AHDS); con las habituales referencias al lugar del que son naturales o vecinos; o bien las informaciones de los centros artísticos/centros de producción donde se tenía por costumbre "publicar la obra". Así las cosas, es un hecho que hacia finales del siglo XVII y, de un modo particular, a lo largo del XVIII la fuerza del aparato de producción se concentró en la Galicia atlántica; dibujándose, de esta suerte, una verdadera red cuyo centro era Santiago de Compostela -pero no exclusivamentey cuyas ramificaciones se extendieron por el área central y sudoccidental.

Además de perfilar el funcionamiento del campo de producción, no quería poner el punto y final sin antes insistir en que, sin querer negar que Santiago de Compostela fue uno de los centros de producción más prestigiosos e influyentes -el cual difundió "repertorios" y formas sobre una extensa área que sin duda sobrepasó los límites de su Diócesis-, hubo otros focos igualmente importantes, como Noia, Pontevedra o Padrón - Iria Flavia43; ignorar sus aportes, es ignorar una parte importante de la "historia" del retablo en la Galicia atlántica.

Por otra parte, se acostumbra a decir que el aparato de producción básicamente se concentró en villas y ciudades; pero esto es verdadero y falso a la vez. Habida cuenta que en el siglo XVIII hubo otros focos de rango menor en el medio rural; como queda probado a través de las noticias que informan del establecimiento de talleres en feligresías de las jurisdicciones de Arousa y en la vega de Padrón.

Ahora bien, el retablo mayor de Nuestra Señora de la Esclavitud no se explica convenientemente al margen de la retablística compostelana y/o sin echar mano de los usos artísticos del entorno de Miguel de Romay. Por consiguiente, hay que llamar la atención sobre la presencia, en las comarcas del Sar y A Maía, de obras de artistas pertenecientes a este círculo; caso de Francisco de Casas -trabajó en el retablo mayor de San Pedro de Bugallido (h. 1743) y, tal vez antes, en San Lorenzo de Seira (h. 1733)- ${ }^{44} y$, de un modo particular, Manuel de Leys. Pero, este último, -a mi juicio- no trabajó en el Santuario de A Escravitude de Cruces; y, si lo hizo, fue tan solo entregando unas trazas que, sin lugar a dudas, llevó a cabo unos de sus colaboradores - ¿tal vez Francisco de Casas?-, junto con José de Malbares. Una tesis que coincide, sin dificultad alguna, con la horquilla cronológica que se fija para la hechura y ensamblaje del altar mayor, esto es: entre 1739-1742/1743. Pero es en la acción de José de Malbares, y, de un modo particular, su presencia en el arciprestazgo de Iria Flavia y la villa de Padrón, cuando todo cobra sentido. 


\section{NOTAS}

${ }^{1}$ Este trabajo se contextualiza en la actividad investigadora del grupo IACOBUS (GI-1907) de la Universidade de Santiago de Compostela (USC), en la que el autor colabora; realizado dentro de los proyectos financiados por el Ministerio de Ciencia e Innovación, dentro del Plan Nacional de I+D+i, titulado Encuentros, intercambios y presencias en Galicia entre los siglos XVI y XX (HAR2011-22899); y por la Xunta de Galicia en el Programa de Consolidación e Estructuración de Unidades de Investigación Competitivas (GRC2013036). Por otra parte, este trabajo forma parte de la Tesis Doctoral que defendí y me fue aprobada en 2011: I. REGA CASTRO, Los retablos mayores en el sur de la diócesis de Santiago de Compostela durante el siglo XVIII (17001775). Iglesia, cultura y poder [Recurso electrónico], Santiago de Compostela, Universidade de Santiago de Compostela, 2011, pp. 587-595.

2 «Al notario que passo desde esta villa a Nuestra señora de la Esclavitud en busca de Maestro de obras señalado por el señor provisor para el reconocimiento y estado de la iglesia no le allo, vino buscandole a su casa feligresía de Valga donde durmió aquel dia y al siguiente llegaron a esta villa [...]», Libro de Fábrica (1732-1867), leg. 1, fols. 174 v. y 176 v.-177 r., Administración parroquial, Santiago de Carril, Arousa, Archivo Histórico Diocesano de Santiago (AHDS). Aunque pasó desapercibida, la noticia fue recopilada por M. A. TILVE JAR, Aportación documental al estudio histórico-artístico del arciprestazgo de Arousa: (Siglos XVI-XX), Memoria de Licenciatura, bajo la dirección de José Manuel García Iglesias, Universidade de Santiago de Compostela, Facultade de Xeografía e Historia, 1986, p. 156-157.

${ }^{3}$ A. LÓPEZ, Nuevos estudios crítico-históricos acerca de Galicia (introducción y notas por L. Gómez Canedo), Madrid, Consejo Superior de Investigaciones Científicas, Instituto P. Sarmiento de Estudios Gallegos, 1947, 2, p. 228235. Cfr. J. CARDESO LIÑARES, Santuarios marianos de Galicia: historia, arte y tradiciones, A Coruña, Fundación Caixa Galicia, 1995, p. 81-83.
${ }^{4}$ R. OTERO TÚÑEZ, "Excursiones por Galicia: el santuario de la Esclavitud", en Boletín de la Universidad de Santiago de Compostela, 57-60 (19511952), p. 78-85. Citar por extenso una bibliografía actualizada del santuario de A Escravitude y su retablo mayor haría excesivamente pesado y repetitivo el aparato crítico (vid. notas núm. 14 y 15); así que simplemente referiré -a la espera de un trabajo monográfico de investigación-, junto a las referencias ya clásicas de Atanasio López, Couselo Bouzas y Otero Túñez, los apuntes de García Iglesias sobre su arquitectura, J. M. GARCÍA IGLESIAS, El Barroco (II): Arquitectos del siglo XVIII, otras actividades artísticas, Galicia. Arte, A Coruña, Hércules, 1993, 14, p. 153-154.

${ }^{5}$ «Ajuste y remate que se hizo de la Gloriosa Parroquial de san Miguel de Valga, obligación que otorgó Angel Antonio Mouriño de hazerla en la cantidad de ocho mill nuebezientos y zinquenta reales», dado en la feligresía de Valga, a 1 de noviembre de 1739, Libro de Fábrica (1652-1766), leg. 1, fols. 222 r.- 226 r., Administración parroquial, San Miguel de Valga, Iria Flavia, AHDS. Cit. J. COUSELO BOUZAS, Galicia artística en el siglo XVIII y primer tercio del XIX (ed. facs. 1932 y 1933), Santiago de Compostela, Instituto Teológico Compostelano, 2005, p. 471

${ }^{6}$ «[...] en cuiua virtud dicho rector despachó papeletas a la villa del Padrón, villa de Caldas y otras partes para que llegase a noticia de los maestros del arte a fin de que concurriesen I a hacer sus posturas, que lo vinieron haciendo Gregorio de fontenla, Juan de fontenla, vezinos de la feligresía de S. Pedro de Dimo, dicho Angel Antonio Mouriño, Blas y Antonio Diz vezinos de la feligresía de san Martín de laje, jurisdicción de los Vaños [...]», Libro de Fábrica (1652-1766), leg. 1, fol. 222 r.-v., Administración parroquial, San Miguel de Valga, Iria Flavia, AHDS.

${ }^{7}$ Catastro de Ensenada, Respuestas Generales, Provincia de Santiago, L. 252 (Mic. 78), fol. 681 v., Arquivo Histórico Universitario de Santiago de Compostela (AHUS), o bien, Catastro de Ensenada, Respuestas Generales, L. 242, fol. 127 v. [AGS_CE_RG_ L242_129.jpg], Dirección General de Rentas, $1^{a}$ Remesa, Archivo General de Simancas (AGS.). En: Portal de Archivos Españoles (PARES) - Ministerio de Educación, Respuestas Generales del Catastro de Ensenada: recursos [en línea] <http://pares.mcu.es/Catastro/ servlets/ServletController.> (Consulta: 05/04/2013)

8 «[Condiciones:] Que todo dicho retablo ha de ser dorado de buen oro. La escultura que en el se halla tambien ha de ser dorada y estofada como lo pide la obra. Encima del dicho oro se le han de dar los bronceados que corresponden por las partes necesa, rias para que sobre salga el oro que quedare en limpio. Que en las partes que fueren necessarias y combenientes, se le han de dar los colores de verde esmeralda, y carmin. Que todas las frutas y florestas que se hallan en dicho retablo, tambien se han de estofar: y todas las bandas y colgajes han de ser bañados de diferentes colores en la comformacion que oy se prattica. Que el rreparo del sagrario se haga todo con la dezencia que fuere mas posible para quede conducente a la más obras. Que el pedestal de piedra ha de ser colorido con diferentes jaspes al olio. Y que todos los Angeles que ay en dicho retablo han de ser de pintura encarnada según se estila con sus cabellos plateados dandole el color que corresponde [...]», Prot. Benito Paizal, 1743, s/cat. (sin catalogar), fol. 22 r., Padrón, Arquivo Histórico Universitario de Santiago de Compostela (AHUS). Cit. J. COUSELO BOUZAS, Galicia artística en el siglo XVIII..., op. cit., p. 273.

${ }^{9}$ D. L. GONZÁLEZ LOPO, "Onomástica y devoción: La difusión de nuevos cultos marianos en la Galicia meridional durante los siglos XVIII y XIX: El Obispado de Tui", en Obradoiro de Historia Moderna, 1, 1992, p. 172.

10 Prot. Domingo Antonio Sánchez, 1749, leg. 3.788, fol. 14 r.-v., Santiago de Compostela, AHUS. Cit. J. COUSELO BOUZAS, Galicia artística en el siglo XVIII..., op. cit., p. 413.

${ }^{11}$ Ibidem, fol. $14 \mathrm{r}$.

12 R. OTERO TÚÑEZ, "Excursiones por Galicia...", op. cit., p. 78.

${ }^{13}$ Constituciones para el Régimen y gobierno de la Real y devota Cofradía de María Santísima de la Esclavitud, que para su mayor culto y veneración se estableció canónicamente y con Real 
aprobación, en su hermoso Santuario, construido á expensas de sus devotos bienhechores, en términos de la parroquia de Santa María de Cruces en este Arzobispado, en el año 1771, Santiago de Compostela, Imprenta de Juan Rey Romero, 1849, p. 10-11. En: Santuario de la Esclavitud, Mazo 1, Antecedentes sobre su administración y gobierno (1769-1886), leg. 1.20.1., Fondo General, Santuarios, AHDS.

14 J. M. LÓPEZ VÁZQUEZ, "Inventariado e catalogación do patrimonio moble: metodoloxía e problemática", en C. FONTENLA SAN JUAN (dir.), Os profesionais da Historia da Arte ante $O$ Patrimonio Cultural, Santiago de Compostela, Xunta de Galicia, 1996, p. 62.

${ }^{15}$ M. C. FOLGAR DE LA CALLE, "El retablo barroco gallego", en J. M. GARCÍA IGLESIAS (dir.), Galicia no Tempo. Conferencias y otros estudios, Santiago de Compostela, 1992, p. 218. J. M. GARCÍA IGLESIAS, El Barroco (II): Arquitectos del siglo XVIII, otras actividades artísticas, Galicia. Arte, A Coruña, Hércules, 1993, 14, p. 415.

16 R. OTERO TÚÑEZ, "El retablo mayor de San Martín Pinario", en Cuadernos de Estudios Gallegos, 11 (1956), p. 229-231. M. C. FOLGAR DE LA CALLE, "La iglesia de San Martín Pinario de Santiago de Compostela: su amueblamiento", en [Actas de] Monjes y monasterios españoles, Madrid, Instituto Escurialense de Investigaciones históricas y artísticas, 1995, 1, p. 171172. M. C. FOLGAR DE LA CALLE, J. M. LÓPEZ VÁZQUEZ, "La iglesia. Los retablos", en J. M. GARCÍA IGLESIAS (dir.), Santiago. San Martín Pinario, Santiago de Compostela, Xunta de Galicia, 1999, p. 261.

17 R. OTERO TÚÑEZ, "Excursiones por Galicia...", op. cit., p. 85. El uso y ornamento de los órdenes clásicos en la retablística barroca ha generado una numerosa bibliografía artística que no cabe citar aquí por extenso; me limito a llamar la atención sobre un par de referencias en la historiografía gallega más reciente, pero sin entrar en el debate acerca de la denominación "columna panzuda", desde Otero Túñez, I. REGA CASTRO, "De la columna panzuda al estípite: el retablo barroco en el noroeste de la Península Ibérica y las con- secuencias de la Reforma Católica", en [Actas de] IV Congresso Internacional do Barroco Ibero-Americano [Archivo de ordenador], 2006, Ouro Preto, Brasil, Universidade Federal de Minas Gerais, Universidade Federal de Ouro Preto, Universidad Pablo de Olavide, 2006/2008, pp. 137-152. Ibídem, "Barroco de estípites en Santo Estevo de Ribas de Sil, o la incógnita acerca de los obradores benedictinos del siglo XVIII", en E. FERNÁNDEZ CASTIÑEIRAS, J. M. MONTERROSO MONTERO (dir), Entre el agua y el cielo. El patrimonio monástico de la Ribeira Sacra. Opus Monasticorum V, Santiago de Compostela, Universidade de Santiago de Compostela, 2012, pp. 191-215.

18 J. M. LÓPEZ VÁZQUEZ, "Inventario e Catalogación do Patrimonio moble...", op. cit., p. 61-62.

19 I. REGA CASTRO, "Los talleres de escultura y talla de Noia (17301775): apuntes sobre la retablística del Barroco en el arciprestazgo de Posmarcos de Arriba", en Compostellanum, 53, 3-4 (2008), p. 520.

20 J. COUSELO BOUZAS, Galicia artística en el siglo XVIII..., op. cit., p. 437.

21 J. COUSELO BOUZAS, Galicia artística en el siglo XVIII..., op. cit., p. 437. M. MONTOTO FEIJÓO, "El culto y la Capilla de Santa María la Blanca en la S.I. Catedral de Santiago de Compostela (notas para una monografía)", en Cuadernos de estudios gallegos, 7 (1947), p. 422.

22 J. J. MARTíN GONZÁLEZ, El artista en la sociedad española del siglo XVII, Madrid, Cátedra, 1984, p. 276 y 279.

${ }^{23}$ M. I. PÉREZ PIÑEIRO, "Aportación documental al estudio históricoartístico del arciprestazgo de Ponte Beluso", en Cuadernos de estudios gallegos, 47, 113 (2000), p. 286.

${ }^{24}$ M. MURGUÍA, El Arte en Santiago durante el siglo XVIII y noticia de los artistas que florecieron en dicha ciudad y centuria, Madrid, Tip.de Ricardo Fé, 1884 , p. 221

${ }_{25}$ M. A. TILVE JAR, "Aportación documental al estudio histórico-artístico del Arciprestazgo de Arousa (S. XVI-XX): índice de artistas", op. cit., p. 282. Ídem, "La actividad del escultor
José de Malvárez en el Arciprestazgo de Arousa", en Museo de Pontevedra, 58 (2004), p. 109-123.

$26 \mathrm{~J}$. COUSELO BOUZAS, Galicia artística en el siglo XVIII..., op. cit., p. 437.

27 M. A. TILVE JAR, "Aportación documental al estudio histórico-artístico del Arciprestazgo de Arousa...", op. cit., 282 p. Ídem, "La actividad del escultor José de Malvárez...", op. cit., p. 113-123.

${ }^{28}$ A. RODRÍGUEZ FRAIZ, "O Retábulo do altar maor de San Pedro de Campañó, obra dos mestres Bento Rey Rodríguez Liñariños e Xosé de Malvárez", en Museo de Pontevedra, 44, 1990, p. 461-462.

${ }^{29}$ A. GOY DIZ, Artistas, talleres e gremios en Galicia (1600-1650), Santiago de Compostela, Servicio de Publicacións da Universidade, USC, 1998, p. 65-66.

30 Libro de fábrica (1709-1790), leg. 2, fol. 23 r., Administración parroquial, Santa Columba de Louro, Cordeiro, Iria Flavia, AHDS.

31 Santísimo Sacramento (17171954), leg. 2, fol. 83 r., Cofradías e Instituciones parroquiales, San Pedro de Lantaño, Ribadumia, AHDS.

32 A. ROdRíguez FRAIZ, "O Retábulo do altar maor de San Pedro de Campañó...", op. cit., p. 467.

33 Libro de fábrica (1709-1790), leg. 2, fol. 320 r., Administración parroquial, Santa Columba de Louro, Cordeiro, Iria Flavia, AHDS.

${ }^{34}$ A. FRAGUAS Y FRAGUAS, "La villa y tierra de Padrón en el Catastro de Ensenada", en Cuadernos de Estudios Gallegos, 29 (1974-1975), p. 258.

${ }^{35}$ Catastro de Ensenada, Respuestas Generales, Provincia de Santiago, L. 252 (Mic. 78), fol. 681 v., AHUS.

${ }^{36}$ R. OTERO TÚÑEZ, "Excursiones por Galicia...", op. cit., p. 84.

${ }^{37}$ R. M. ANDERSON, Una mirada de antaño: fotografías de Ruth Matilda Anderson en Galicia, supervisión y coordinación Patrick Lenaghan. A Coruña: Fundación Caixa Galicia; New York : The Hispanic Society of America, 2009, Cat. Anderson 1808.

${ }^{38} \mathrm{M}$. C. FOLGAR DE LA CALLE, Simón Rodríguez, A Coruña, Funda- 
ción Pedro Barrié de la Maza, 1989, p. 76-78.

39 J. M. GARCÍA IGLESIAS, El Barroco (II): Arquitectos del siglo XVIII..., op. cit., 14, p. 415.

${ }^{40}$ R. OTERO TÚÑEZ, "Del Barroco al Rococó: retablos e imágenes de la iglesia compostelana de las Huérfanas", en Abrente, 26 (1994), p. 20-27.

${ }^{41}$ R. OTERO TÚÑEZ, "Los retablos del crucero de san Martín Pinario", en Boletín de la Universidad Compostelana, 64 (1956), p. 279-282. Cfr. M. C. FOLGAR DE LA CALLE, J. M. LÓPEZ VÁZQUEZ, "La iglesia. Los retablos", op. cit., p. 261-269.
${ }^{42}$ La teoría de los centros artísticos es una metodología que cuajó en los años 1980, a partir de los esfuerzos de J. J. Martín González, quien se preocupó por situar dónde se produjo el arte -con auxilio de la geografía y la estadística-, en J. J. MARTín GONZÁLEZ, El artista en la sociedad española del siglo XVII, op. cit., p. 280 y ss. Cfr. J. J. MARTíN GONZÁLEZ, "Centros artísticos de la provincia de Cáceres (siglos XVI al XVIII)", Actas del VII congreso de estudios extremeños, 1, 1983, p. 11-21.

${ }^{43}$ Justamente, en cuanto a actividades artísticas, Beiró Piñeiro sacó a la luz un tejido socio-profesional en «[...] la Villa de Padrón, su casco y termino» más complejo del que cabía esperar, que da cuenta de la importancia de la cantería y, a la par, de los oficios relacionados con la madera, vid. X. C. BEIRÓ PIÑEIRO, Historia do Convento de Carmelitas Descalzos de San Xosé da Vila de Padrón (1698-1877), Xunta de Galicia, Dirección Xeral de Patrimonio Cultural, 2008, p. 49-52.

${ }^{44}$ J. COUSELO BOUZAS, Galicia artística en el siglo XVIII..., op. cit., p. 245. G. GENDE FRANQUEIRA, El arte religioso en la Mahia, op. cit., 114 y 117-118 p. Cfr. I. REGA CASTRO, Los retablos mayores en el sur de la diócesis de Santiago de Compostela durante el siglo XVIII..., op. cit., p. 431-432 y 439. 